\title{
Impact of nanoscale pore sizes on the flow of gas mixtures in marcellus shale reservoir
}

Noor Mazher Alfashkhi

Follow this and additional works at: https://researchrepository.wvu.edu/etd

\section{Recommended Citation}

Alfashkhi, Noor Mazher, "Impact of nanoscale pore sizes on the flow of gas mixtures in marcellus shale reservoir" (2016). Graduate Theses, Dissertations, and Problem Reports. 5060.

https://researchrepository.wvu.edu/etd/5060

This Thesis is protected by copyright and/or related rights. It has been brought to you by the The Research Repository @ WVU with permission from the rights-holder(s). You are free to use this Thesis in any way that is permitted by the copyright and related rights legislation that applies to your use. For other uses you must obtain permission from the rights-holder(s) directly, unless additional rights are indicated by a Creative Commons license in the record and/ or on the work itself. This Thesis has been accepted for inclusion in WVU Graduate Theses, Dissertations, and Problem Reports collection by an authorized administrator of The Research Repository @ WVU. For more information, please contact researchrepository@mail.wvu.edu. 
Impact of nanoscale pore sizes on the flow of gas mixtures in marcellus shale reservoir

Noor Mazher Alfashkhi

Thesis submitted to Statler College of Engineering and Mineral Resources at West Virginia University

in partial fulfillment of the requirements for the degree of

\author{
Master of Science \\ in \\ Petroleum and Natural Gas Engineering
}

Kashy Aminian, Committee Chairperson

Samuel Ameri, Prof.

Mehradad Zamirian, Ph.D.

Department of Petroleum and Natural Gas

Morgantown, West Virginia

2016

Keywords: Viscosity, Nanopores, Pore Proximity, Confinement, z-Factor. Copyright 2016 Noor M. Alfashkhi 


\section{Abstract \\ THE IMPACT OF PORE CONFINEMENT ON SHALE GAS PROPERTIES \\ Noor Mazher Alfashkhi}

Pore proximity effect in shale reservoirs, unlike the conventional reservoirs, is very significant because the shale matrix contains pores in the range of nano meter that impact the phase behavior and fluid properties of the gas mixtures. The changes to the critical properties of the natural gas impacts the storage and flow in shale matrix. For optimization of gas extraction, understanding the gas properties is of great research interest.

In this research the impact of confinement on the gas viscosity and compressibility factor were evaluated using two typical composition of Marcellus shale gas. The results are to be used in formulating a new calculation method for gas storage and flow in shale reservoirs.

The results of the study indicate that the compressibility factor and viscosity of natural gas is changed by the pore proximity effect. The extent of gas properties change due to confinement depends on the composition of the gas mixture and the size of the nano-pores. Using two gas samples from Marcellus Shale, it was found that the viscosity and z-factor of confined gas deviated by an average of $20 \%$ and $6 \%$ respectively when compared to unconfinedgases. 


\section{ACKNOWLEDGMENTS}

I wish to first thank almighty GOD for without his benevolence and unceasing blessings, this research would not have been at all possible. Also, it is a pleasure to express my sincere appreciation to my mentor and thesis advisor Dr. Kashy Aminian for his guidance and support. I am as well grateful to my committee members, Dr. Mehrdad Zamirian for his time, and Professor Samuel Ameri for always being helpful and encouraging during my years in the university.

Gratitude is extended to Dr. Shahab Mohaghegh, Dr. H. Ilkin Bilgesu, Dr. Ali Takbiri, Ms. Beverly Matheny and everyone who taught and supported me throughout my years of study at the department of Petroleum and Natural Gas Engineering.

Finally, there are people in everyone's life who makes success both possible and worthwhile, I must express my deep gratitude to my parents and my partner for showering me with their love and their unfailing support and encouragement. This achievement would not have been possible without them. 
TABLE OF CONTENTS

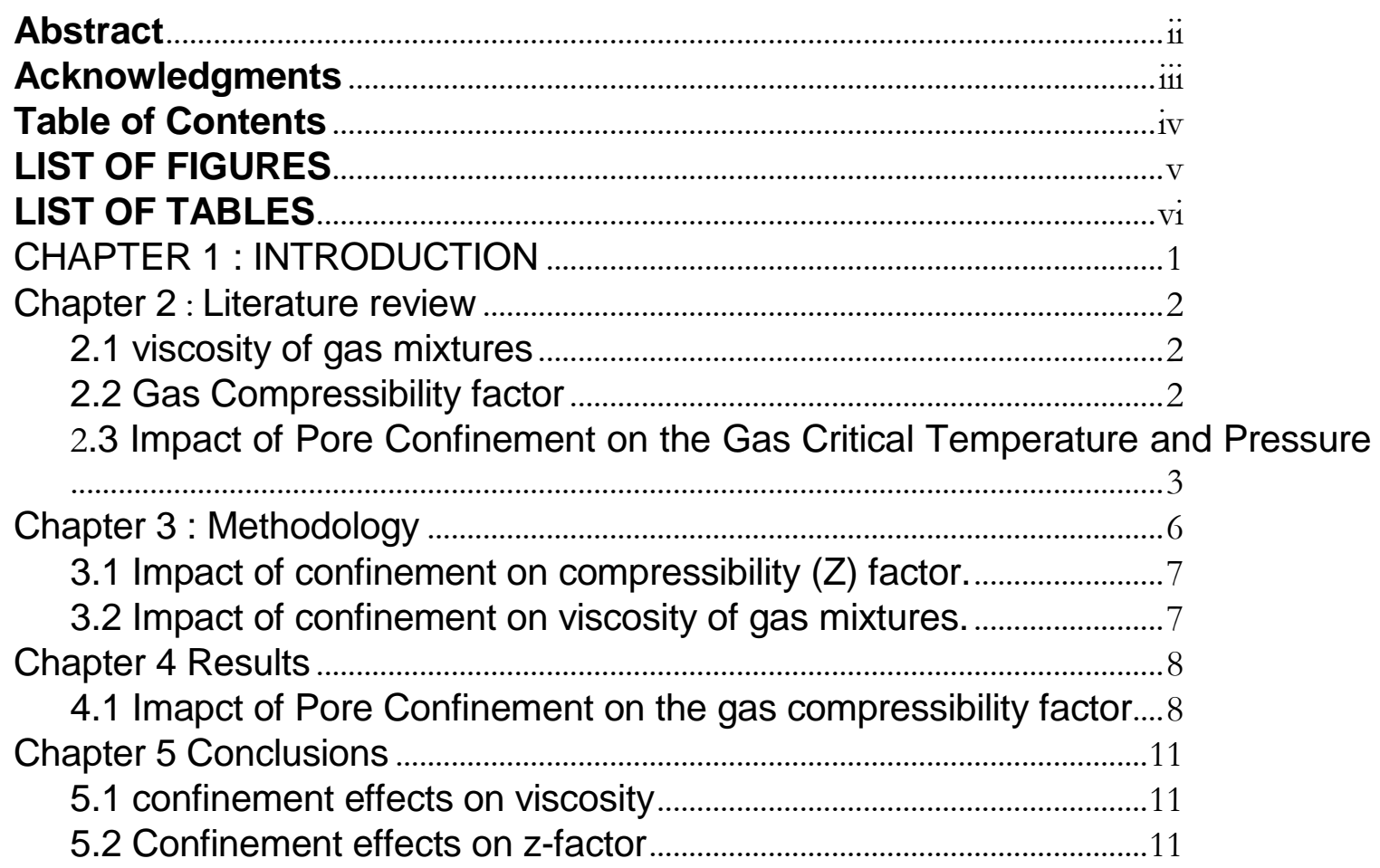




\section{LIST OF FIGURES}

FIGURE 2-1 PHASE DIAGRAM (CLARK 2004)....

4

FIGURE 2-2 IMPACT OF NANOPORE SIZES ON GAS CRITICAL PRESSURE (DEVEGOWDA 2012).................... 5

FIGURE 2-3 IMPACT OF NANOPORE SIZES ON GAS CRITICAL TEMPERATURE (DEVEGOWDA 2012) ................5

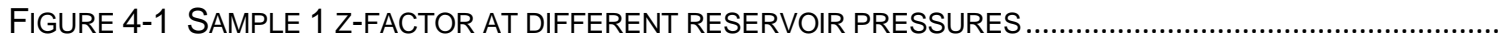

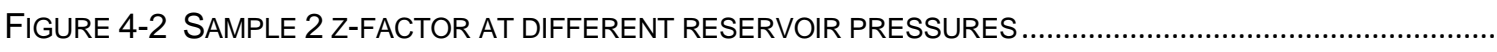

FIGURE 4-3 CHANGE IN VISCOSITY FOR THE CHANGE IN RESERVOIR PRESSURE (SAMPLE 1) ........................ 10

FIGURE 4-4 CHANGE IN VISCOSITY FOR THE CHANGE IN RESERVOIR PRESSURE (SAMPLE 2) ....................... 10 


\section{LIST OF TABLES}

TABLE 2-1 PROPOSED CORRELATION FOR DETERMINING THE SHIFT OF CRITICAL PRESSURE AND TEMPERATURE.

TABLE 3-1 MARCELLUS SHALE GAS COMPOSITIONS. 4

TABLE 3-2 RESERVOIR TEMPERATURE AND PRESSURE.

TABLE 4-1 PERCENT CHANGE IN VISCOSITY FROM THE UNCONFINED GAS (SAMPLE 1).

TABLE 4-2 PERCENT CHANGE IN VISCOSITY FROM THE UNCONFINED GAS (SAMPLE 2 )

TABLE 5-1 PERCENT CHANGE OF VISCOSITY...

TABLE 5-2 PeRCENT Change OF COMPRESSIBILITY FACTOR. 


\section{CHAPTER 1 : INTRODUCTION}

The Marcellus Shale is an abundant source of natural gas, and according to the U.S. Energy Information Administration, most of the natural gas consumed in the states comes from domestic production. The advances in technology such as hydraulic fracturing and horizontal drilling that uncovered a substantial amount of hydrocarbons accumulated in shale formations have increased the domestic production. Even though advances in technology have proven successful, the characteristics of the rock and the presence of nanoscale pores have created new challenges for the development of the reserves. Understanding the effects that nano pores have on the behavior of hydrocarbons within the shale formation can improve estimation of the gas in place and increase the production efficiency.

Reservoir analysis and prediction has been an integral necessity of the Oil \& Gas industry for decades. Understanding reservoir components have allowed for better production efficiency and investment decision making. Conventional methods of modelling hydrocarbon reservoirs have been utilized by reservoir engineers, geologists, and industry professionals for years. With the development of new technology, unconventional resources have brought a wave of growth within the United States Shale has taken its place as being the most explored and produced unconventional hydrocarbon reservoir in the modern era of oil \& gas. With the advent of an industry overcome with unconventional shale production, its analysis and development of its production techniques, became a significant topic for lots of researchers.

When pore sizes decrease, the flow mechanism of fluids through the pores is changed and no longer follow Darcy's law of fluid flow (Curtis et al., 2010). Therefore, properties of the gas such as compressibility, and viscosity will be analyzed for different pore sizes. The results of the analysis will then be used to determine the gas in place and measure the gas flow rate in shale formations. 


\section{Chapter 2 : Literature review}

\section{1 viscosity of gas mixtures}

Viscosity is the internal resistance of fluid to flow. For a mixture of gases, the viscosity can be evaluated if the composition as well as the viscosity of each component is available (McCain, 1990).

$\mu_{g a}=\frac{\sum_{i=1}^{N} y_{i} \mu_{i} \sqrt{M_{g i}}}{\sum_{i=1}^{N} y_{i} \sqrt{M_{g i}}}$

Where, $\mu_{g a}$ is the viscosity of the gas mixture at atmospheric pressure, $y_{i}$ is the mole fraction of each component of the gas mixture, $\mu_{i}$ is the viscosity of each individual component at atmospheric pressure, and $M_{g i}$ as well as $N$ are the molecular weight and number of components in the gas mixture respectively.

The viscosity of each component of natural gas mixture at a given pressure and temperature can be determined by using a correlation chart (Appendix) that rely on the pseudo reduced values of temperature and pressure (Carr et al., 1954).

\subsection{Gas Compressibility factor}

Assumptions in the current kinetic theory of gases (McCain, 1990) states that gas molecules which are completely separated from each other have the same average velocity, have the same mass, the interactions among gas particles is negligible, and the molecules are perfectly round and are elastic in nature. Gases following these assumptions, are known as ideal gases.

In realty however, gas particles do interact with each other and only at high temperature and pressure they stay far apart and so their interaction as well as their relative volume are insignificant. Real gases under such conditions are said to behave ideally.

To account for the deviation of gases from there ideal state, a correction factor is used. This correction factor is called gas compressibility factor or Z-factor. The z-factor can be estimated using Standing and Katz chart (appendix) that utilizes the pseudo-reduced temperature and pressure obtained from the pseudo-critical pressure and temperature. The pseudo-critical pressure and temperature may simply be expressed as the summation of the molar critical pressure and temperature of the gas mixture components (McCain, 1990). Hence:

$p_{p c}=\sum y_{i} p_{c i}$
$T_{p c}=\sum y_{i} T_{c i}$ 
Where $p_{p c}$ and $T_{p c}$ are the pseudo-critical pressure and temperature of the gas mixture, $p_{c i}$ and $T_{c i}$ are the critical pressure and temperature of component $i$ in the gas mixture while $y_{i}$ is the mole fraction of component $i$ in the gas mixture.

$T_{p c}=\sum y_{i} T_{c i}$
$P_{p c}=\sum y_{i} p_{c i}$
$T_{p r}=T_{r} / T_{p c}$
$P_{p r}=P_{r} / P_{p c}$

Where $p_{p c}$ and $T_{p c}$ are the pseudo-critical pressure and temperature of the gas mixture, $p_{c i}$ and $T_{c i}$ are the critical pressure and temperature of component $i$ in the gas mixture while $y_{i}$ is the mole fraction of component $i$ in the gas mixture.

\subsection{Impact of Pore Confinement on the Gas Critical Temperature and Pressure}

When defining gases, properties such as pressure and temperature are usually used. Any change in pressure and temperature inside the reservoir will cause a change to the behavior and maybe the phase of the gas. Figure 2-1 shows when each phase starts and end, and the critical point (point $C$ in Fig 2-1) in which the gas turns to liquid. 


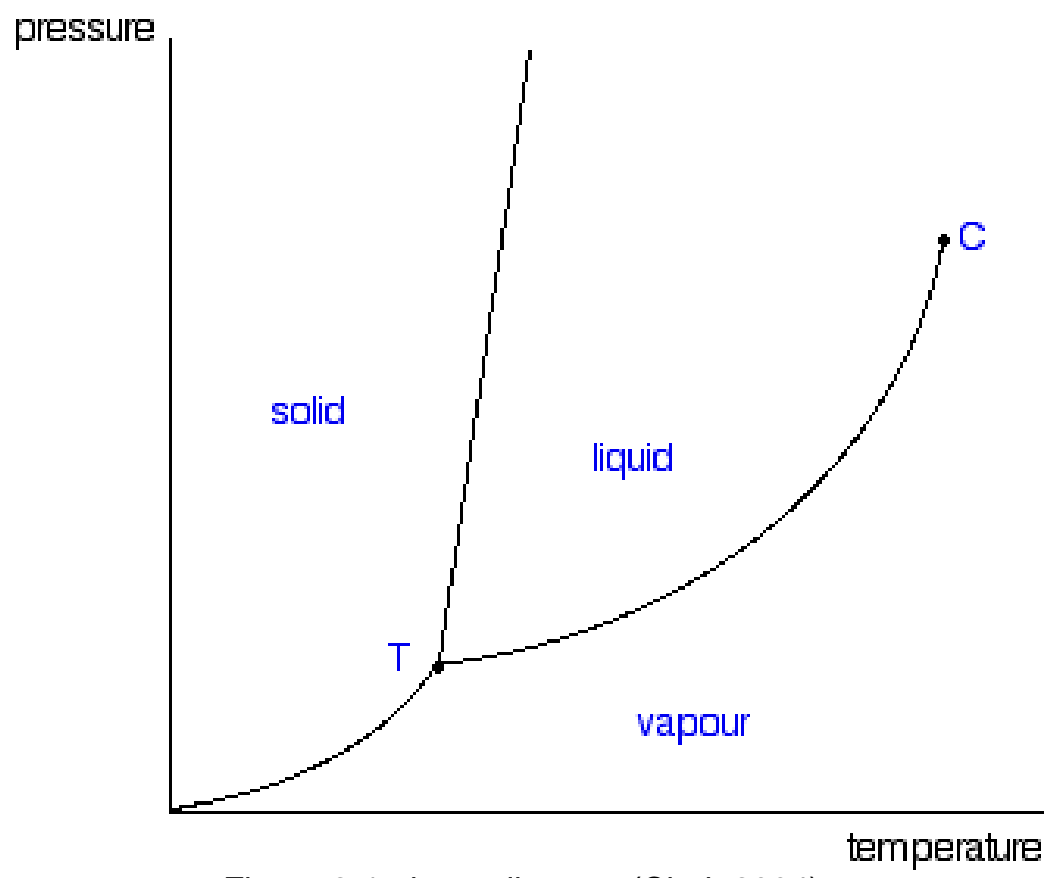

Figure 2-1 phase diagram (Clark 2004)

Over the years many studies have been conducted to analyze the effect pore confinement has on the critical properties of gas from their bulk values. Singh et al. (2009) studied the shift in critical properties and proposed equations describing the shift in methane, n-butane, and n-octane. Later, Devegowda et al. (2012) extended the work of Singh and proposed correlations (table 2-1) for measuring the deviation of critical pressure and temperature of the heavier gases confined in the nano-pore sizes of 2,4 , and $5 \mathrm{~nm}$. Figures $2-2$ and 2-3 show the deviation in critical temperature and pressure with respect to the molecular weight of the gas.

Table 2-1 Proposed Correlation for determining the shift of critical pressure and temperature

\begin{tabular}{|c|c|l|}
\hline \multirow{4}{*}{$\Delta P_{c}$} & $2 \mathrm{~nm}$ & $0.085 \ln (\mathrm{MW})-0.0693$ \\
\cline { 2 - 3 } & $4 \mathrm{~nm}$ & $-0.085 \ln (\mathrm{MW})+0.1193$ \\
\cline { 2 - 3 } & $5 \mathrm{~nm}$ & $-0.077 \ln (\mathrm{MW})-0.041$ \\
\hline \multirow{3}{*}{$\Delta T_{c}$} & $2 \mathrm{~nm}$ & $0.0636(\mathrm{MW}) 0.2129$ \\
\cline { 2 - 3 } & $4 \mathrm{~nm}$ & $0.0229(\mathrm{MW}) 0.2319$ \\
\cline { 2 - 3 } & $5 \mathrm{~nm}$ & $0.0153(\mathrm{MW}) 0.241$ \\
\hline
\end{tabular}

$\Delta T_{c}=\frac{T_{c b}-T_{c p}}{T_{c b}}$

$\Delta P_{c}=\frac{P_{c b}-P_{c p}}{P_{c b}}$

Where $T_{c b}$ and $P_{c b}$ are the critical temperature and pressure of the bulk fluid, and $T_{c p}$ as well as $P_{c p}$ are their equivalent values in confined pores. 


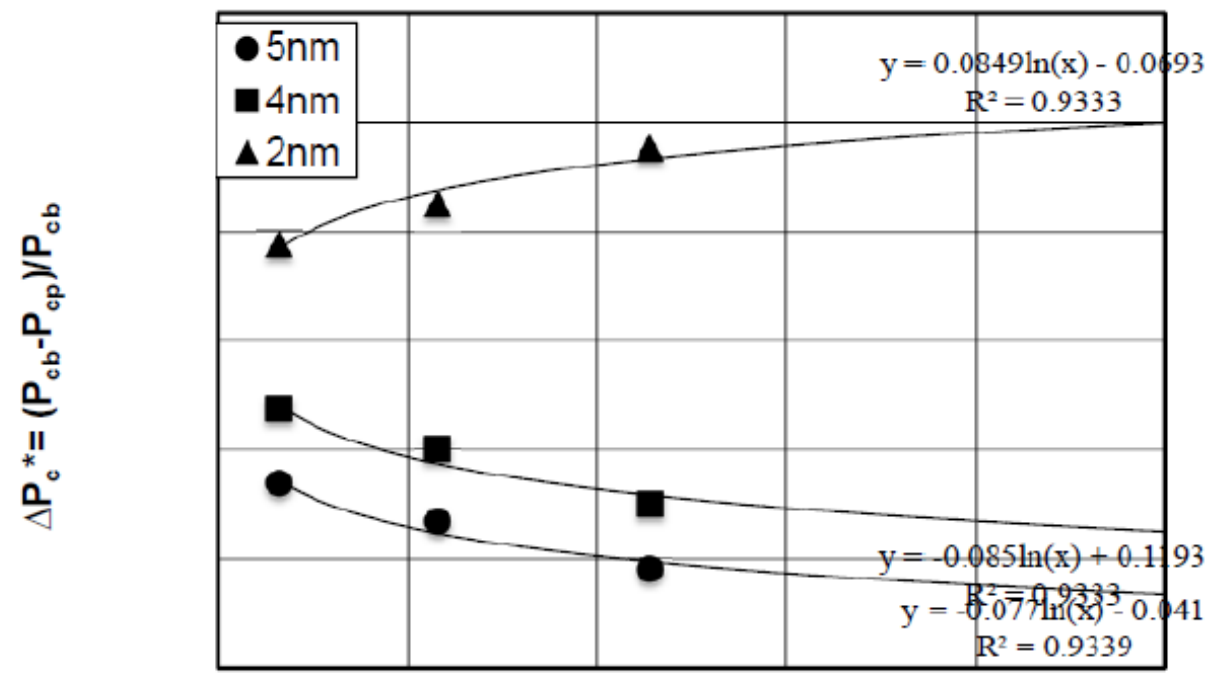

\section{Molecular Weight}

Figure 2-2 Impact of Nanopore Sizes on gas critical pressure (Devegowda 2012).

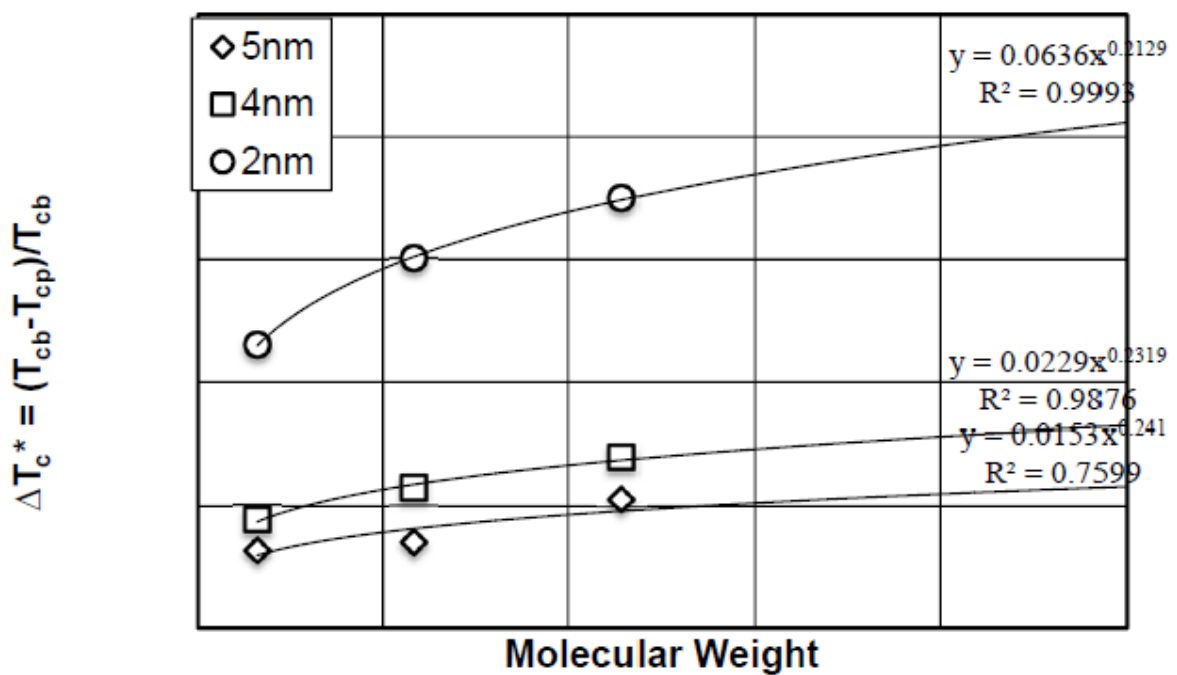

Figure 2-3 Impact of Nanopore Sizes on gas critical temperature (Devegowda 2012). 


\section{Chapter 3 : Methodology}

The objective of this research was to study and understand the effect pore proximity has on the natural gas found in Marcellus shale formation. Mainly its effect on compressibility and viscosity of the gas.

To meet the objective of this study, two different gas compositions from two different areas within the Marcellus (Table 3-1), were utilized to measure and compare the viscosity as well as the deviation factor of the gas confined within the pores.

Table 3-1 Marcellus Shale Gas Compositions

\begin{tabular}{|c|c|c|}
\hline \multicolumn{3}{|c|}{ Mole fraction } \\
\hline component & sample 1 & sample 2 \\
\hline CO2 & 0.00156 & 0.00089 \\
\hline N2 & 0.00465 & 0.00355 \\
\hline C1 & 0.77299 & 0.74308 \\
\hline C2 & 0.14775 & 0.15185 \\
\hline C3 & 0.04885 & 0.05874 \\
\hline i-C4 & 0.00573 & 0.00714 \\
\hline n-C4 & 0.01156 & 0.01717 \\
\hline i-C5 & 0.00239 & 0.0037 \\
\hline n-C5 & 0.0023 & 0.00537 \\
\hline C6 & 0.00129 & 0.005 \\
\hline C7+ & 0.00093 & 0.0035 \\
\hline
\end{tabular}

The relative shift in critical properties of each component were estimated by utilizing Singh et al. equations and Devegowda's et al. correlations for the confined pores listed in the literature review. A set of reservoir temperature and pressure (Table 3-2) were used in the evaluation process of gas properties. 
Table 3-2 Reservoir Temperature and Pressure

\begin{tabular}{|c|c|}
\hline$P($ psia $)$ & $T\left({ }^{\circ} R\right)$ \\
\hline 3000 & 574.69 \\
\hline 3100 & 576.69 \\
\hline 3200 & 578.69 \\
\hline 3300 & 580.69 \\
\hline 3400 & 582.69 \\
\hline 3500 & 584.69 \\
\hline 3600 & 586.69 \\
\hline 3700 & 588.69 \\
\hline 3800 & 589.69 \\
\hline 3900 & 592.69 \\
\hline 4000 & 594.69 \\
\hline
\end{tabular}

\subsection{Impact of confinement on compressibility (Z) factor.}

The pseudo-critical and pseudo-reduced values of pressure and temperature were calculated using the equations provide in the literature review, and the results were used for estimating the real gas deviation factor from Standing and Katz Z-factor chart (Appendix).

\subsection{Impact of confinement on viscosity of gas mixtures.}

The viscosity of the gas confined in 2, 4, and 5 nanometer pores were calculated using the compositional analysis as well as pseudo-reduced properties of the gas found in the previous section. The viscosity at one atmospheric pressure and reservoir temperature is determined first using the gas mixture composition equation (2.1), and then, multiplying the result by the viscosity ratio of each component obtained from Carr's diagram (Appendix) of the effect temperature and pressure has on the viscosity of natural gas. 


\section{Chapter 4 Results}

\subsection{Imapct of Pore Confinement on the gas compressibility factor}

The z-factor for the two samples of shale used in this study were determined using the compressibility chart mentioned in the literature review. The estimated values of the z-factor for the confined gas in the shale matrix are compared to the unconfined (base) mixture. The plots below show the deviation of z-factor for various reservoir pressures and pore sizes of 2, 4, and 5 nanometers in diameter.

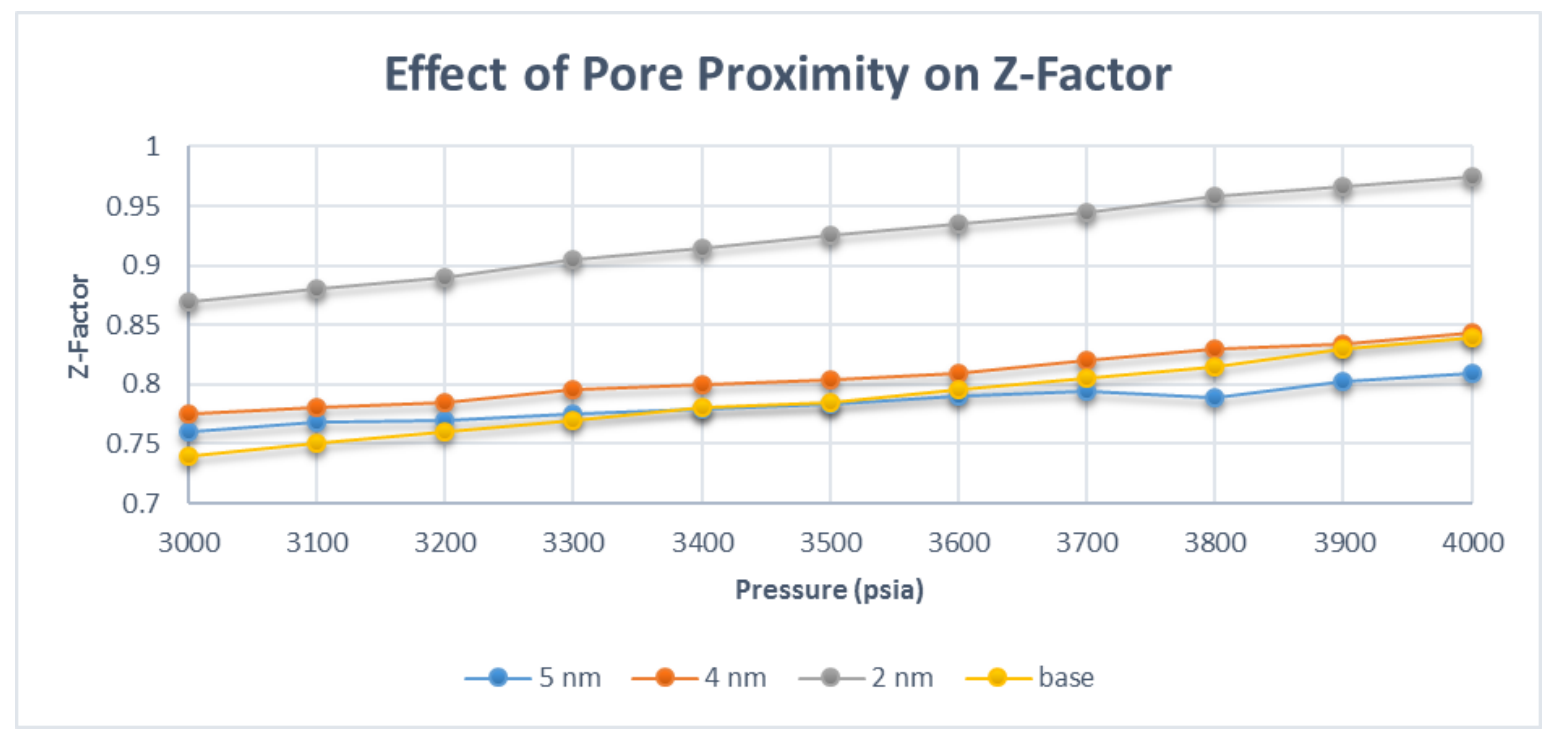

Figure 4-1 Sample $1 \mathrm{z}$-factor at different reservoir pressures

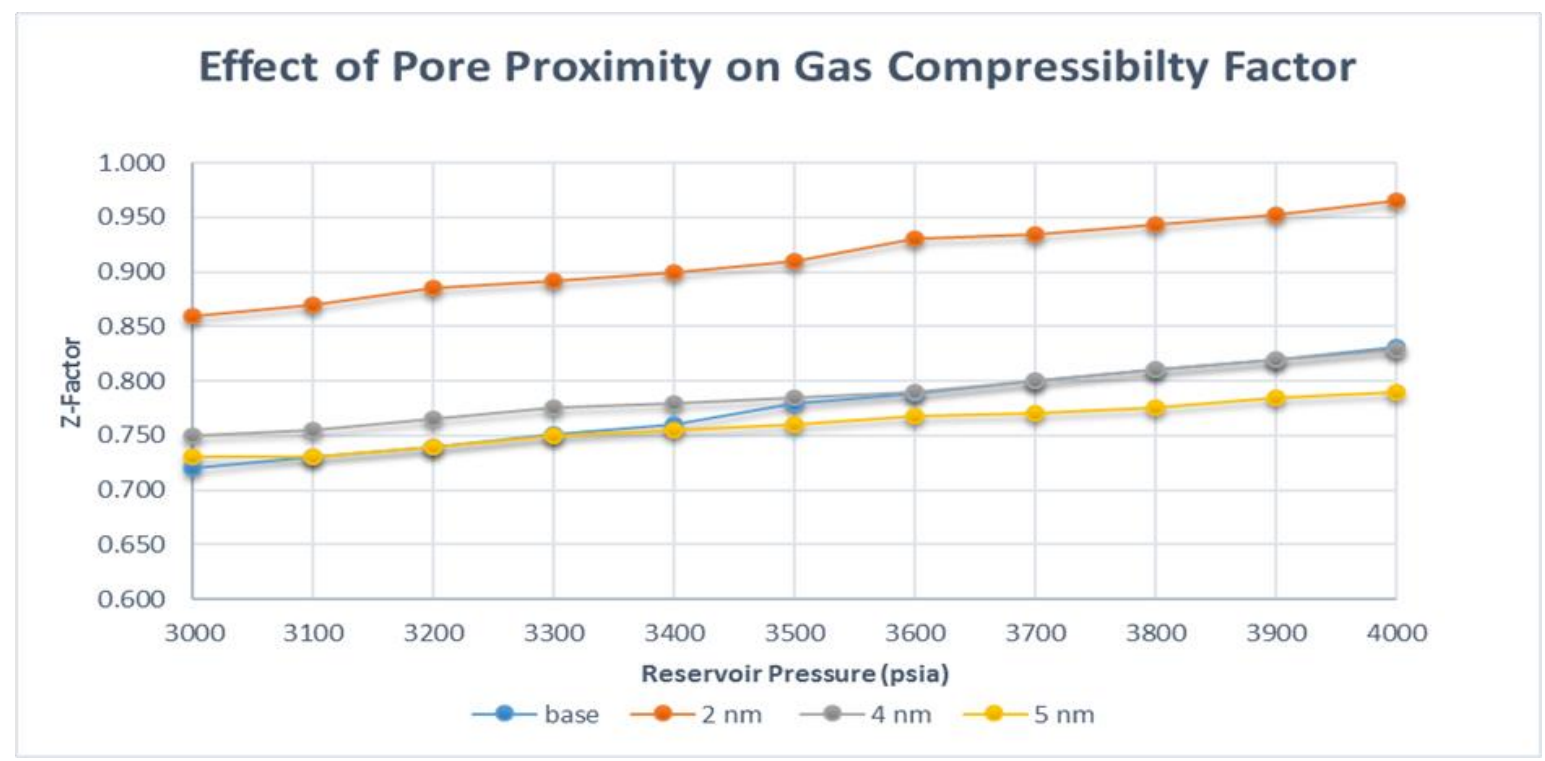

Figure 4-2 Sample 2 z-factor at different reservoir pressures 


\subsection{Confinement effect on the viscosity.}

The viscosity was measured using the method proposed in the methodology, and the results for the confined gas in 2, 4, and 5 nanometer sized pores were compared to the viscosity of unconfined (base) gas. The following tables (4-1 and 4-2) and Figures 6 and 7 show the percent change due to confinement as well as the deviation of viscosity compared the change in reservoir pressure:

Table 4-1 Percent change in viscosity from the unconfined gas (sample 1)

\begin{tabular}{|c|c|c|c|}
\hline \multicolumn{5}{|c|}{$\%$ Change in Viscosity (Sample 1) } \\
\hline $\boldsymbol{P}$ (psia) & $2 \mathrm{~nm}$ pore size & $4 \mathrm{~nm}$ pore size & $5 \mathrm{~nm}$ pore size \\
\hline 3000 & $-15 \%$ & $-20 \%$ & $-20 \%$ \\
\hline 3100 & $-15 \%$ & $-19 \%$ & $-20 \%$ \\
\hline 3200 & $-16 \%$ & $-21 \%$ & $-21 \%$ \\
\hline 3300 & $-15 \%$ & $-19 \%$ & $-20 \%$ \\
\hline 3400 & $-14 \%$ & $-19 \%$ & $-20 \%$ \\
\hline 3500 & $-14 \%$ & $-17 \%$ & $-21 \%$ \\
\hline 3600 & $-15 \%$ & $-19 \%$ & $-24 \%$ \\
\hline 3700 & $-14 \%$ & $-19 \%$ & $-24 \%$ \\
\hline 3800 & $-15 \%$ & $-19 \%$ & $-23 \%$ \\
\hline 3900 & $-13 \%$ & $-19 \%$ & $-23 \%$ \\
\hline 4000 & $-13 \%$ & $-20 \%$ & $-23 \%$ \\
\hline
\end{tabular}

Table 4-2 Percent change in viscosity from the unconfined gas (sample 2)

\begin{tabular}{|c|c|c|c|}
\hline \multicolumn{4}{|c|}{$\%$ Change in Viscosity (Sample 2) } \\
\hline $\boldsymbol{P}$ (psia) & $2 \mathrm{~nm}$ pore size & $4 \mathrm{~nm}$ pore size & $5 \mathrm{~nm}$ pore size \\
\hline 3000 & $-20 \%$ & $-21 \%$ & $-23 \%$ \\
\hline 3100 & $-19 \%$ & $-21 \%$ & $-23 \%$ \\
\hline 3200 & $-18 \%$ & $-19 \%$ & $-23 \%$ \\
\hline 3300 & $-19 \%$ & $-21 \%$ & $-22 \%$ \\
\hline 3400 & $-19 \%$ & $-20 \%$ & $-23 \%$ \\
\hline 3500 & $-19 \%$ & $-19 \%$ & $-23 \%$ \\
\hline 3600 & $-19 \%$ & $-20 \%$ & $-24 \%$ \\
\hline 3700 & $-18 \%$ & $-19 \%$ & $-22 \%$ \\
\hline 3800 & $-18 \%$ & $-20 \%$ & $-22 \%$ \\
\hline 3900 & $-18 \%$ & $-19 \%$ & $-22 \%$ \\
\hline 4000 & $-19 \%$ & $-19 \%$ & $-24 \%$ \\
\hline
\end{tabular}




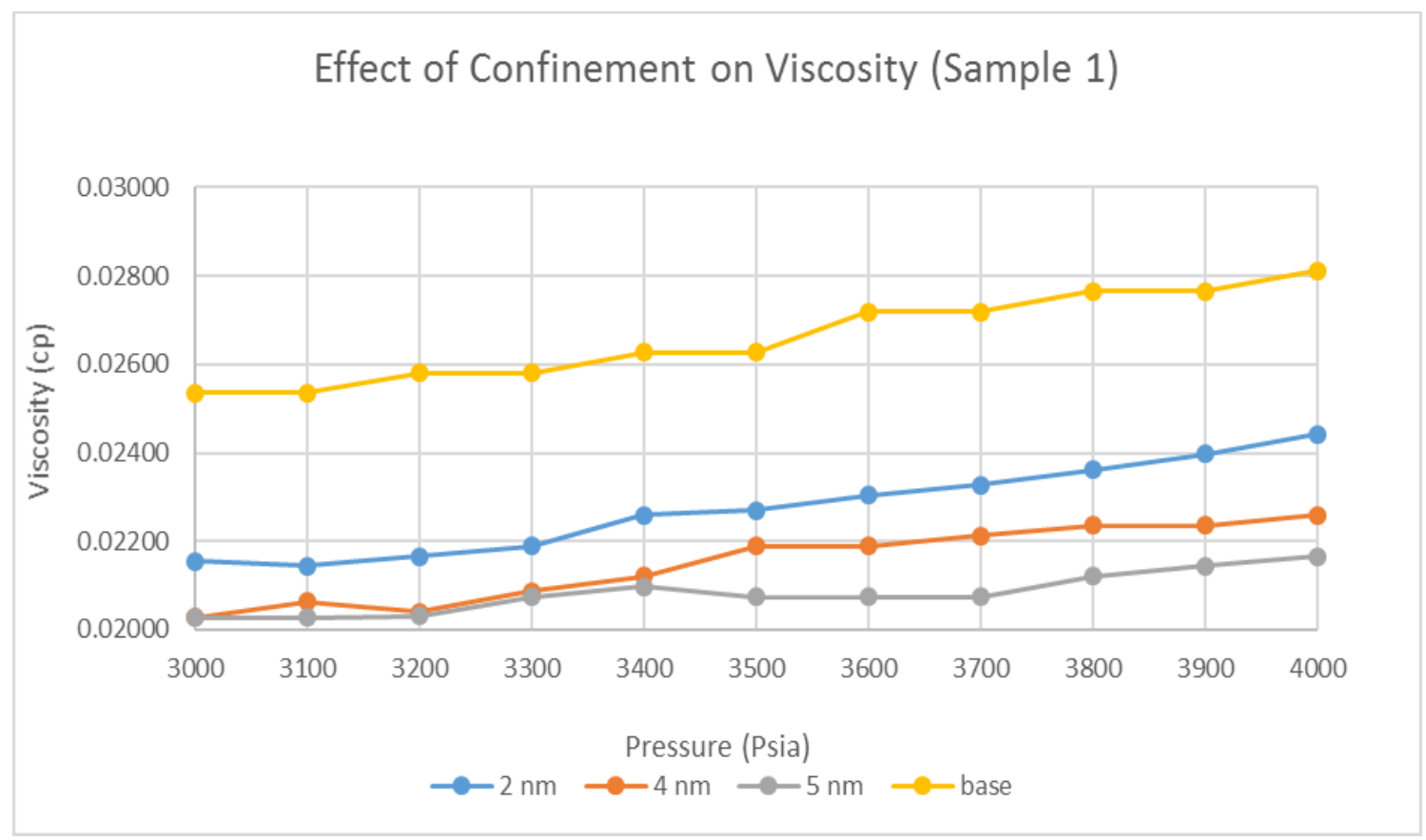

Figure 4-3 change in viscosity for the change in reservoir pressure (sample 1)

\section{Effect of Confinement on Viscosity (Sample 2)}

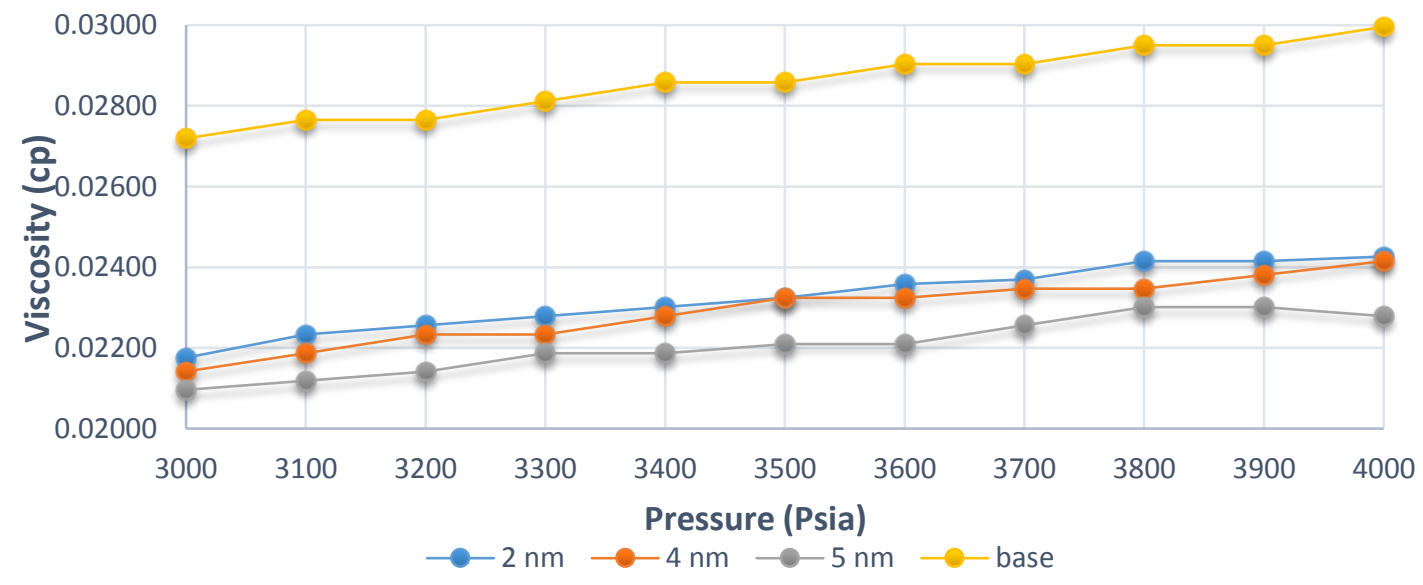

Figure 4-4 change in viscosity for the change in reservoir pressure (sample 2) 


\section{Chapter 5 Conclusions}

In this research three cases of confined pores with pore sizes of 2, 4, and 5 nanometers were used to study the impact they have on the viscosity and compressibility of the gas by comparing the results to the case of unconfined pores.

The results have shown that nanopores impact the viscosity and the compressibility factor of the gas. The most observed effect occurs when pore sizes are 2 nanometers in diameter, as shown in tables $5-1$ and $5-2$.

\section{1 confinement effects on viscosity}

Table 5-1 Percent Change of viscosity

\begin{tabular}{|c|c|c|}
\hline pore size & sample 1 & sample 2 \\
\hline $2 \mathrm{~nm}$ & $-15 \%$ & $-19 \%$ \\
\hline $4 \mathrm{~nm}$ & $-19 \%$ & $-20 \%$ \\
\hline $5 \mathrm{~nm}$ & $-22 \%$ & $-23 \%$ \\
\hline
\end{tabular}

A decrease in pore size decreases the viscosity. Change in viscosity impacts flow rate, the higher the viscosity means that hydrocarbons will flow more slowly, therefore, when pores are 2 nanometers in diameter where the viscosity is at its lowest the hydrocarbons will flow much faster.

\subsection{Confinement effects on z-factor}

Table 5-2 Percent Change of compressibility factor

\begin{tabular}{|c|c|c|}
\hline pore size & sample 1 & sample 2 \\
\hline $2 \mathrm{~nm}$ & $17 \%$ & $18 \%$ \\
\hline $4 \mathrm{~nm}$ & $2 \%$ & $1 \%$ \\
\hline $5 \mathrm{~nm}$ & $-1 \%$ & $-2 \%$ \\
\hline
\end{tabular}

While smaller pores have a positive impact on the viscosity of the gas, it impacts the estimation of original gas in place negatively. A smaller pore size leads to an increase in z-factor and therefore an over estimation of gas reserves. 


\section{B I B L I O G R A P H Y}

Alharthy, N. S., Nguyen, T., Teklu, T., Kazemi, H., \& Graves, R. (2013, September 30). Multiphase Compositional Modeling in Small-Scale Pores of Unconventional Shale Reservoirs. Society of Petroleum Engineers. doi:10.2118/166306-MS

Allawe, E. M., Stockdale, A. P., Aminiaa, K., \& Ameri, S. (2015, October 13). Impact of Nanoscale Pore Confinement on Estimation of Gas Resources and Gas/Condensate Behavior in Shale Reservoirs. Society of Petroleum Engineers. doi:10.2118/177285-MS

Carr, N.L., Kobayashi, R., and Burrows, D.B. 1954. Viscosity of Hydrocarbon Gases Under Pressure. J Pet Technol 6 (10): 47-55. SPE-297-G. http://dx.doi.org/10.2118/297-G

Devegowda, D., Sapmanee, K., Civan, F., \& Sigal, R. F. (2012, January 1). Phase Behavior of Gas Condensates in Shales Due to Pore Proximity Effects: Implications for Transport, Reserves and Well Productivity. Society of Petroleum Engineers. doi:10.2118/160099-MS

Jin, Z., \& Firoozabadi, A. (2015, September 28). Phase Behavior and Flow in Shale Nanopores From Molecular Simulations. Society of Petroleum Engineers. doi:10.2118/175151-MS

Sakhaee-Pour, A., \& Bryant, S. (2012, August 1). Gas Permeability of Shale. Society of Petroleum Engineers. doi:10.2118/146944-PA

Shi, J., Zhang, L., Li, Y., Yu, W., He, X., Liu, N., .. Wang, T. (2013, November 5). Diffusion and Flow Mechanisms of Shale Gas through Matrix Pores and Gas Production Forecasting. Society of Petroleum Engineers. doi:10.2118/167226-MS

Swami, V., Clarkson, C. R., \& Settari, A. (2012, January 1). Non-Darcy Flow in Shale Nanopores: Do We Have a Final Answer? Society of Petroleum Engineers. doi:10.2118/162665-MS

William D. McCain. (1990). The properties of petroleum fluids. PennWell Books.

Zamirian, M., Aminian, K., Fathi, E., \& Ameri, S. (2014, October 21). A Fast and Robust Technique for Accurate Measurement of the Organic-rich Shales Characteristics under Steady-State Conditions. Society of Petroleum Engineers. doi:10.2118/171018-MS 


\section{ApPendiX}

Table A- 1 Critical temperature and pressure for unconfined gas

\begin{tabular}{|c|c|c|}
\hline component & $\begin{array}{c}\text { Critical } \\
\text { Temperature (R) }\end{array}$ & $\begin{array}{c}\text { Critical } \\
\text { Pressure } \\
\text { (psia) }\end{array}$ \\
\hline CO2 & 548 & 1072 \\
\hline N2 & 227 & 492 \\
\hline C1 & 344 & 673 \\
\hline C2 & 550 & 709 \\
\hline C3 & 666 & 618 \\
\hline i-C4 & 733 & 530 \\
\hline n-C4 & 766 & 551 \\
\hline i-C5 & 830 & 482 \\
\hline n-C5 & 847 & 485 \\
\hline C6 & 915 & 434 \\
\hline C7+ & 973 & 397 \\
\hline
\end{tabular}

Table A- 2 Critical Temperature and Pressure for Confined pores

\begin{tabular}{|c|c|c|c|c|c|c|}
\hline \multirow{2}{*}{ Component } & \multicolumn{2}{|c|}{$\mathbf{2} \mathbf{n m}$ pore } & \multicolumn{2}{c|}{ 4 nm pore } & \multicolumn{2}{c|}{$5 \mathbf{n m}$ pore } \\
\cline { 2 - 7 } & $P c(p s i a)$ & $T c R$ & $P c(p s i a)$ & $T c R$ & $P c(p s i a)$ & $T c R$ \\
\hline CO2 & 801.45 & 469.99 & 1288.95 & 517.82 & 1428.33 & 527.13 \\
\hline N2 & 386.73 & 197.65 & 572.67 & 215.74 & 638.42 & 219.25 \\
\hline C1 & 560.89 & 304.50 & 751.46 & 329.01 & 844.40 & 333.73 \\
\hline C2 & 553.02 & 477.80 & 829.53 & 522.27 & 923.88 & 530.89 \\
\hline C3 & 461.92 & 571.15 & 743.18 & 629.30 & 823.52 & 640.62 \\
\hline $\boldsymbol{i}$-C4 & 383.71 & 622.29 & 649.79 & 689.94 & 717.52 & 703.15 \\
\hline $\boldsymbol{n}$-C4 & 398.92 & 650.31 & 675.53 & 721.00 & 745.95 & 734.80 \\
\hline $\boldsymbol{i}$-C5 & 340.12 & 698.75 & 599.78 & 778.74 & 660.55 & 794.39 \\
\hline $\boldsymbol{n}$-C5 & 342.22 & 713.04 & 603.53 & 794.68 & 664.67 & 810.66 \\
\hline C6 & 299.68 & 764.71 & 546.62 & 856.11 & 600.72 & 874.02 \\
\hline C7+ & 269.04 & 807.97 & 505.11 & 908.14 & 554.12 & 927.81 \\
\hline
\end{tabular}


Table A- 3 Shift in Critical Properties

\begin{tabular}{|c|c|c|c|c|c|c|}
\hline \multirow{2}{*}{ Component } & \multicolumn{3}{|c|}{ shift(Pc) } & \multicolumn{3}{c|}{ shift(Tc) } \\
\cline { 2 - 7 } & $2 \mathrm{~nm}$ pore & $4 \mathrm{~nm}$ pore & $5 \mathrm{~nm}$ pore & $2 \mathrm{~nm}$ pore & $4 \mathrm{~nm}$ pore & $5 \mathrm{~nm}$ pore \\
\hline CO2 & 0.2524 & -0.2024 & -0.3324 & 0.1424 & 0.0551 & 0.0381 \\
\hline N2 & 0.2140 & -0.1640 & -0.2976 & 0.1293 & 0.0496 & 0.0342 \\
\hline C1 & 0.1666 & -0.1166 & -0.2547 & 0.1148 & 0.0436 & 0.0299 \\
\hline C2 & 0.2200 & -0.1700 & -0.3031 & 0.1313 & 0.0504 & 0.0347 \\
\hline C3 & 0.2525 & -0.2025 & -0.3326 & 0.1424 & 0.0551 & 0.0381 \\
\hline i-C4 & 0.2760 & -0.2260 & -0.3538 & 0.1510 & 0.0587 & 0.0407 \\
\hline n-C4 & 0.2760 & -0.2260 & -0.3538 & 0.1510 & 0.0587 & 0.0407 \\
\hline i-C5 & 0.2944 & -0.2444 & -0.3704 & 0.1581 & 0.0618 & 0.0429 \\
\hline n-C5 & 0.2944 & -0.2444 & -0.3705 & 0.1582 & 0.0618 & 0.0429 \\
\hline C6 & 0.3095 & -0.2595 & -0.3841 & 0.1642 & 0.0644 & 0.0448 \\
\hline C7+ & 0.3223 & -0.2723 & -0.3958 & 0.1696 & 0.0667 & 0.0464 \\
\hline
\end{tabular}

Table A- 4 Estimated Z-Factors for Sample one

\begin{tabular}{|c|c|c|c|}
\hline \multicolumn{4}{|c|}{ Sample 1 } \\
\hline$Z$ (base) & $Z$ (2nm pore) & $Z$ (4nm pore) & $Z$ (5nm pore) \\
\hline 0.74 & 0.87 & 0.775 & 0.76 \\
\hline 0.75 & 0.88 & 0.78 & 0.768 \\
\hline 0.76 & 0.89 & 0.785 & 0.77 \\
\hline 0.77 & 0.905 & 0.795 & 0.775 \\
\hline 0.78 & 0.915 & 0.8 & 0.779 \\
\hline 0.785 & 0.925 & 0.804 & 0.784 \\
\hline 0.795 & 0.935 & 0.81 & 0.79 \\
\hline 0.805 & 0.945 & 0.82 & 0.794 \\
\hline 0.815 & 0.958 & 0.83 & 0.789 \\
\hline 0.83 & 0.967 & 0.834 & 0.802 \\
\hline 0.84 & 0.975 & 0.844 & 0.809 \\
\hline
\end{tabular}


Table A- 5 Estimated z-factors for sample two

\begin{tabular}{|c|c|c|c|}
\hline \multicolumn{4}{|c|}{ Sample 2 } \\
\hline$Z$ (base) & $Z$ (2nm) & $Z$ (4nm) & $Z$ (5nm) \\
\hline 0.72 & 0.86 & 0.75 & 0.73 \\
\hline 0.73 & 0.87 & 0.755 & 0.73 \\
\hline 0.74 & 0.885 & 0.765 & 0.74 \\
\hline 0.751 & 0.892 & 0.776 & 0.75 \\
\hline 0.76 & 0.9 & 0.78 & 0.755 \\
\hline 0.78 & 0.91 & 0.785 & 0.76 \\
\hline 0.789 & 0.93 & 0.79 & 0.768 \\
\hline 0.8 & 0.935 & 0.8 & 0.77 \\
\hline 0.811 & 0.944 & 0.81 & 0.775 \\
\hline 0.82 & 0.952 & 0.819 & 0.785 \\
\hline 0.831 & 0.965 & 0.828 & 0.79 \\
\hline
\end{tabular}

Table A- 6 Pseudo reduced values of temperature and pressure sample one

\begin{tabular}{|c|c|c|c|c|c|c|}
\hline \multirow{2}{*}{ Component } & \multicolumn{2}{|c|}{$2 \mathrm{~nm}$ pore } & \multicolumn{2}{|c|}{$4 \mathrm{~nm}$ pore } & \multicolumn{2}{|c|}{$5 \mathrm{~nm}$ pore } \\
\hline & Ppr (psia) & $T p r R$ & Ppr (psia) & $\operatorname{Tpr} R$ & Ppr (psia) & $\operatorname{Tpr} R$ \\
\hline $\mathrm{CO} 2$ & 5.46 & 1.63 & 3.95 & 1.50 & 3.52 & 1.48 \\
\hline N2 & 5.64 & 1.64 & 4.08 & 1.51 & 3.64 & 1.49 \\
\hline C1 & 5.82 & 1.65 & 4.21 & 1.52 & 3.76 & 1.49 \\
\hline$C 2$ & 6.00 & 1.65 & 4.34 & 1.52 & 3.87 & 1.50 \\
\hline C3 & 6.18 & 1.66 & 4.47 & 1.53 & 3.99 & 1.50 \\
\hline$i-C 4$ & 6.36 & 1.66 & 4.61 & 1.53 & 4.11 & 1.51 \\
\hline$n-C 4$ & 6.55 & 1.67 & 4.74 & 1.54 & 4.23 & 1.51 \\
\hline$i-C 5$ & 6.73 & 1.67 & 4.87 & 1.54 & 4.34 & 1.52 \\
\hline$n-C 5$ & 6.91 & 1.68 & 5.00 & 1.54 & 4.46 & 1.52 \\
\hline C6 & 7.09 & 1.69 & 5.13 & 1.55 & 4.58 & 1.53 \\
\hline$C 7+$ & 7.27 & 1.69 & 5.26 & 1.56 & 4.70 & 1.53 \\
\hline
\end{tabular}


Table A- 7 Pseudo reduced values of temperature and pressure sample two

\begin{tabular}{|c|c|c|c|c|c|c|}
\hline \multirow{2}{*}{ Component } & \multicolumn{2}{|c|}{$\mathbf{2 ~ n m ~ p o r e ~}$} & \multicolumn{2}{c|}{$\mathbf{4} \mathbf{n m}$ pore } & \multicolumn{2}{c|}{$\mathbf{5 m}$ pore } \\
\cline { 2 - 7 } & $P p r(p s i a)$ & $T p r R$ & $P p r(p s i a)$ & $T p r R$ & $P p r(p s i a)$ & $T p r R$ \\
\hline$C O 2$ & 5.50 & 1.59 & 3.96 & 1.46 & 3.54 & 1.44 \\
\hline N2 & 5.69 & 1.59 & 4.09 & 1.46 & 3.65 & 1.44 \\
\hline$C 1$ & 5.87 & 1.60 & 4.23 & 1.47 & 3.77 & 1.45 \\
\hline$C 2$ & 6.05 & 1.60 & 4.36 & 1.47 & 3.89 & 1.45 \\
\hline$C 3$ & 6.24 & 1.61 & 4.49 & 1.48 & 4.01 & 1.46 \\
\hline$i-C 4$ & 6.42 & 1.61 & 4.62 & 1.48 & 4.12 & 1.46 \\
\hline$n-C 4$ & 6.60 & 1.62 & 4.75 & 1.49 & 4.24 & 1.47 \\
\hline$i-C 5$ & 6.79 & 1.63 & 4.89 & 1.49 & 4.36 & 1.47 \\
\hline$n-C 5$ & 6.97 & 1.63 & 5.02 & 1.50 & 4.48 & 1.47 \\
\hline$C 6$ & 7.15 & 1.64 & 5.15 & 1.50 & 4.60 & 1.48 \\
\hline$C 7+$ & 7.34 & 1.64 & 5.28 & 1.51 & 4.71 & 1.49 \\
\hline
\end{tabular}

Table A- 8 Composition and critical viscosity of gas sample one

\begin{tabular}{|c|c|c|c|c|}
\hline component & Mole fraction $y \mathbf{i}$ & $\mathbf{M i}$ & viscosity & viscosity ${ }^{*} \boldsymbol{y i}$ \\
\hline CO2 & 0.00156 & 44.01 & 0.016 & 0.00002496 \\
\hline N2 & 0.00465 & 28.01 & 0.019 & 0.00008835 \\
\hline C1 & 0.77299 & 16.04 & 0.012 & 0.00927588 \\
\hline C2 & 0.14775 & 30.07 & 0.0102 & 0.00150705 \\
\hline C3 & 0.04885 & 44.1 & 0.009 & 0.00043965 \\
\hline $\boldsymbol{i}$-C4 & 0.00573 & 58.12 & 0.0083 & 0.000047559 \\
\hline $\boldsymbol{n}$-C4 & 0.01156 & 58.12 & 0.008 & 0.00009248 \\
\hline $\boldsymbol{i}$-C5 & 0.00239 & 72.12 & 0.0072 & 0.000017208 \\
\hline $\boldsymbol{n}$-C5 & 0.0023 & 72.15 & 0.007 & 0.0000161 \\
\hline C6 & 0.00129 & 86.18 & 0.0066 & 0.000008514 \\
\hline C7+ & 0.00093 & 100.21 & 0.0062 & 0.000005766 \\
\hline total & 1 & & & 0.011523517 \\
\hline
\end{tabular}


Table A- 9 Composition and critical viscosity of gas sample two

\begin{tabular}{|c|c|c|c|c|}
\hline component & Mole fraction $y \mathbf{i}$ & $\mathbf{M i}$ & viscosity & viscosity * $\boldsymbol{y i}$ \\
\hline CO2 & 0.00089 & 44.01 & 0.016 & $1.42 E-05$ \\
\hline N2 & 0.00355 & 28.01 & 0.019 & $6.75 E-05$ \\
\hline C1 & 0.74308 & 16.04 & 0.012 & 0.008917 \\
\hline C2 & 0.15185 & 30.07 & 0.0102 & 0.001549 \\
\hline C3 & 0.05874 & 44.1 & 0.009 & 0.000529 \\
\hline $\boldsymbol{i}$-C4 & 0.00714 & 58.12 & 0.0083 & $5.93 E-05$ \\
\hline $\boldsymbol{n}$-C4 & 0.01717 & 58.12 & 0.008 & 0.000137 \\
\hline $\boldsymbol{i}$-C5 & 0.0037 & 72.12 & 0.0072 & $2.66 E-05$ \\
\hline $\boldsymbol{n}$-C5 & 0.00537 & 72.15 & 0.007 & $3.76 E-05$ \\
\hline C6 & 0.005 & 86.18 & 0.0066 & 0.000033 \\
\hline C7+ & 0.0035 & 100.21 & 0.0062 & $2.17 E-05$ \\
\hline total & 0.99999 & & & 0.011392 \\
\hline
\end{tabular}




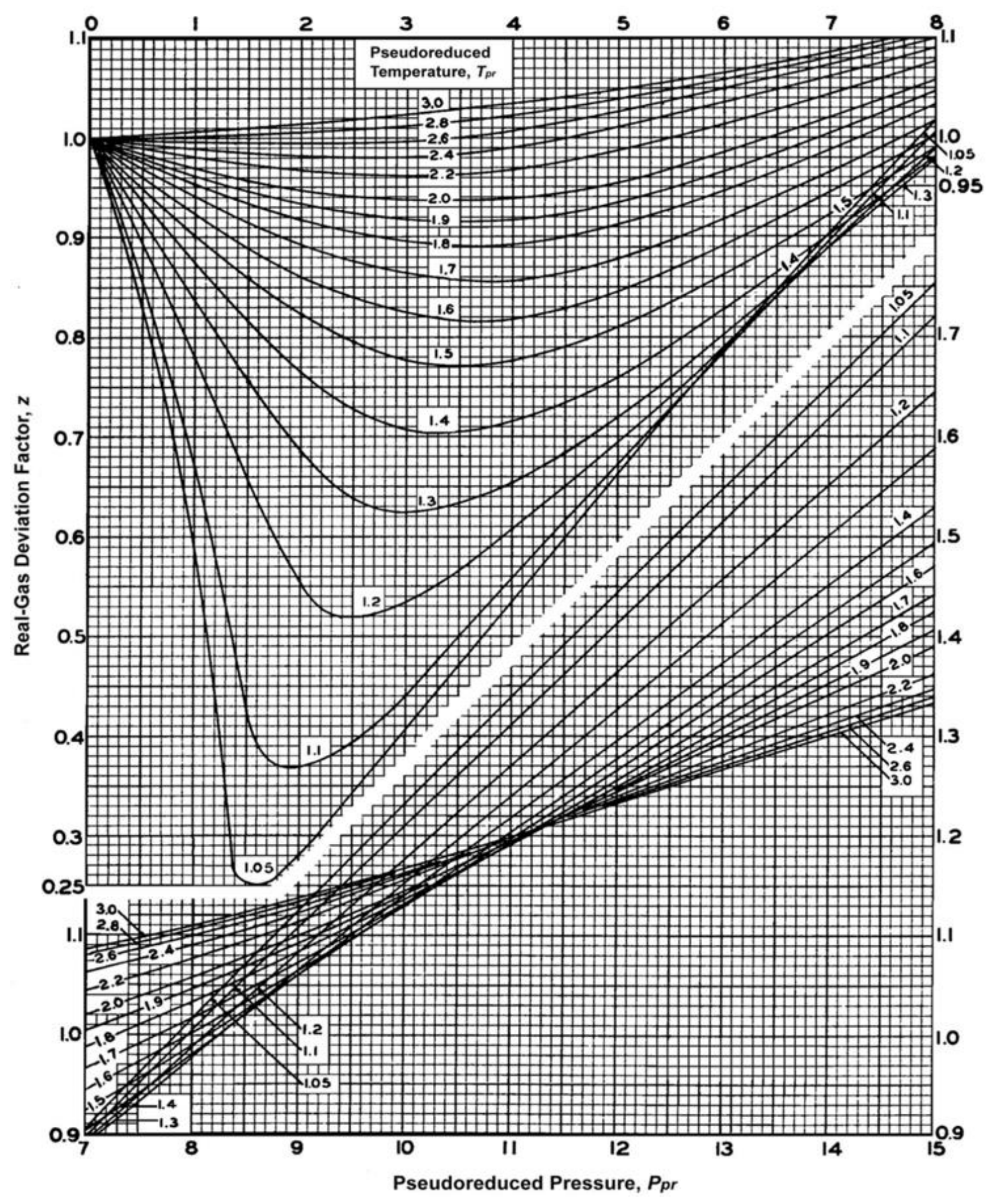

Figure A- 1 Standing and Katz z-factor chart (McCain, 1990) 


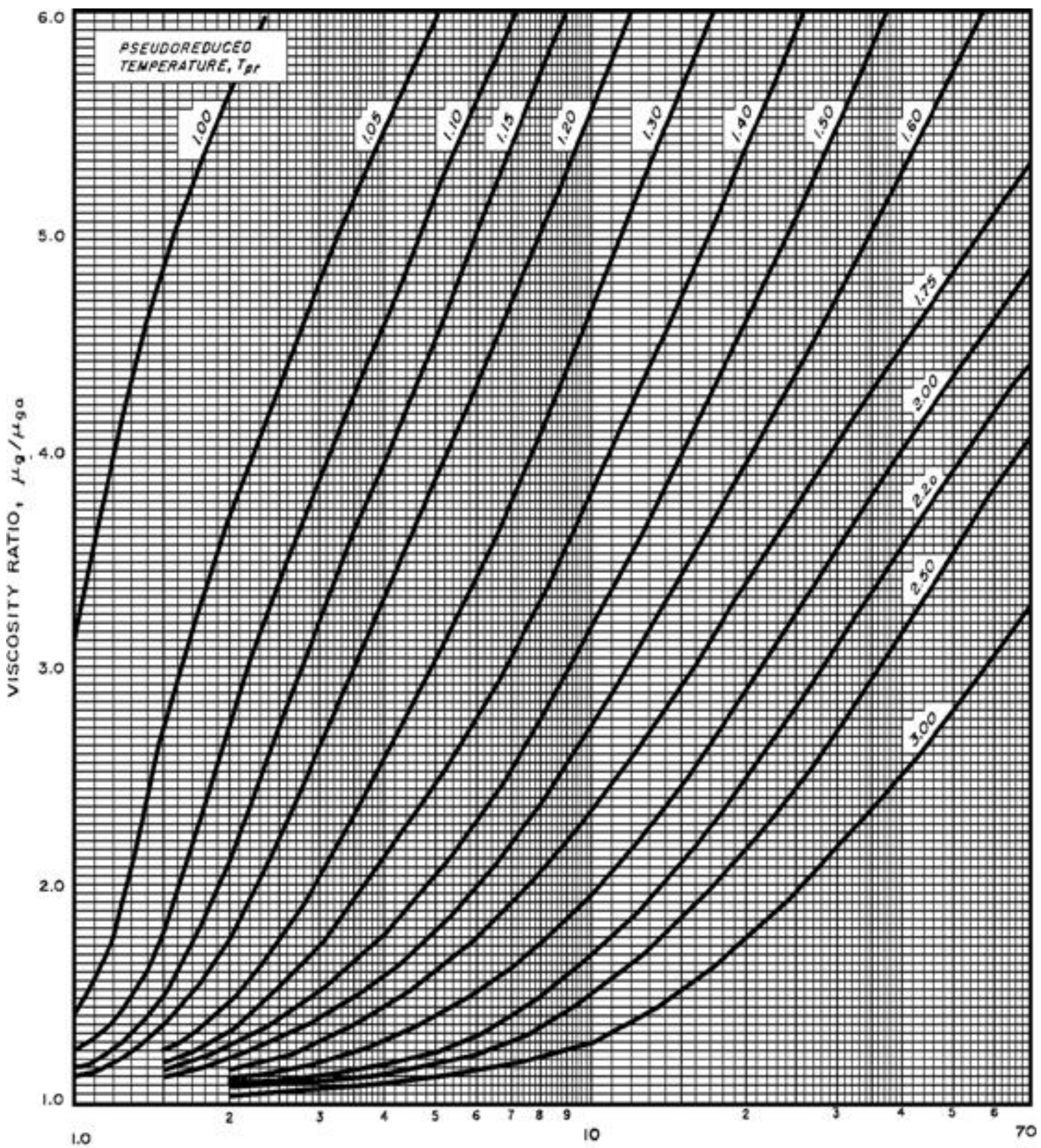

Figure A- 2 Effect of temperature and pressure on viscosity of natural gas (Carr et al., 1954) 